\title{
Structure and Solidification Process Observation of Fe-C-Cr Alloy Using Confocal Laser Scanning Microscope
}

\author{
Shin ITO $^{1 *}$, Hideki KAWAI ${ }^{1}$, Yoshihiko OISHI ${ }^{1}$, and Hiroshi NoGAMI ${ }^{2}$ \\ ${ }^{1}$ Department of Production Systems Engineering, Faculty of Engineering, Muroran Institute of Technology, 27-1, Mizumoto, \\ Muroran, Hokkaido, Japan \\ ${ }^{2}$ Department of Metal Frontier Engineering, Faculty of Engineering, Tohoku University, 2-chome 1-1, Aoba-ku Katahira, Sendai, \\ Miyagi, Japan
}

\begin{abstract}
In this study, we investigated the growth process of $\mathrm{M}_{7} \mathrm{C}_{3}$ carbide by a Confocal Laser Scanning Microscope. Fe-C-Cr alloy was prepared using an arc furnace. The composition was determined to be Fe:C:Cr=55:5:40(wt\%). From the results of XRD and EPMA, the Fe-C-Cr alloy contained $\mathrm{M}_{7} \mathrm{C}_{3}$ carbide in the internal structure. In condition of two cooling rates $60^{\circ} \mathrm{C} / \mathrm{min}$ and $30^{\circ} \mathrm{C} / \mathrm{min}$ observed with a Confocal Laser Scanning Microscope. Corners of the Hexagonal structure grew in the preferred orientation direction of $\mathrm{M}_{7} \mathrm{C}_{3}$ carbide at $60^{\circ} \mathrm{C} / \mathrm{min}$. After the growth of preferred orientation direction, the $\mathrm{M}_{7} \mathrm{C}_{3}$ carbide formed to connect between the corners. At a cooling rate of $30^{\circ} \mathrm{C} / \mathrm{min}, \mathrm{M}_{7} \mathrm{C}_{3}$ carbides grew in oblique direction to the observation area. At the beginning, the structures were hidden in the fluid. But the structures started to grow, the shape of the hexagon became eventually. After the melting experiment, the samples were observed by Optical Microscope and Scanning Electron Microscope. As a result, since hexagonal structure arose a difference in height between the outside and the inside. $\mathrm{M}_{7} \mathrm{C}_{3}$ carbides grew from the outside in the solidification process.
\end{abstract}

\section{Introduction}

The wear-resistant material $\mathrm{Fe}-\mathrm{C}-\mathrm{Cr}$ alloy is generally a ternary white cast iron containing $7 \%$ or more of $\mathrm{Cr}$, and forms a large amount of hard carbides $\mathrm{M}_{23} \mathrm{C}_{6}, \mathrm{M}_{3} \mathrm{C}, \mathrm{M}_{7} \mathrm{C}_{3}$ $(\mathrm{M}=\mathrm{Fe}, \mathrm{Cr})$ (Sato et al., 1958). Hence, it is used for a slurry pump that transfers slurry liquid, and rolling rolls used for rolling. However, the rolling conditions are becoming more severe in terms of energy saving and quality improvement in rolling processing, and the slurry pump has problems of wear and corrosion due to high concentration of slurry liquid. In order to cope with the current situation, it is important to change the solidification structure by adjusting the $\mathrm{Cr}$ content and $\mathrm{C}$ content to improve the low toughness and to improve the corrosion resistance and wear resistance. Changes in composition and cooling rate are related to the mechanical properties of the alloy and affect the solidified structure. Tang et al. (2011) show that the mass separation of $\mathrm{M}_{7} \mathrm{C}_{3}$ carbides increases with the increase of $\mathrm{C}$ content, and the corrosion resistance and wear resistance increase accordingly. In addition, Tong et al. (1990a) revealed that the area fraction of carbides increased with the increase of Cr. The commonly used $\mathrm{Fe}-\mathrm{C}-\mathrm{Cr}$ alloy has a $\mathrm{Cr}$ content of about 12 to $30 \mathrm{wt} \%$. The alloy of this composition is hypoeutectic, Tong et al. (1990b) Fe-C-Cr alloy in the hypoeutectic composition range crystallizes austenite into primary crystals, It is clarified that $\mathrm{Fe}-\mathrm{C}-\mathrm{Cr}$ alloy in the hypereutectic composition range crystallizes $\mathrm{M}_{7} \mathrm{C}_{3}$ carbide in primary crystals. At present, the study of $\mathrm{M}_{7} \mathrm{C}_{3}$ carbides in $\mathrm{Fe}-\mathrm{C}-\mathrm{Cr}$ alloys mainly focuses on its performance. Although there are few studies on the growth mechanism of $\mathrm{M}_{7} \mathrm{C}_{3}$ carbides, Liu et al. (2016) observed in situ 26.3 $\mathrm{Cr}$ cast iron at a cooling rate of $0.1{ }^{\circ} \mathrm{C} / \mathrm{sec}$, and proposed a theory on the growth characteristics of hollow and unclosed shell structures present in the center of $\mathrm{M}_{7} \mathrm{C}_{3}$ carbides. However, the formation process of solidification structure and the growth process of single carbide by the change of cooling rate and composition are not investigated. It is important to clarify the actual growth of the formation structure from direct observation. Direct observation of the solidification process in which carbides and matrix structure appear leads to elucidation of the growth mechanism of $\mathrm{M}_{7} \mathrm{C}_{3}$ carbides, and it can be expected to control the size, amount, and formation position of crystallized materials by changing the cooling rate. In addition, in order to elucidate the growth mechanism of the metal structure, it is necessary to directly observe the metal under high temperature. Therefore, it is essential to use a Confocal Laser Scanning Microscope (CLSM) that is not affected by the radiation emitted from the molten metal. Most common $\mathrm{Fe}-\mathrm{C}-\mathrm{Cr}$ alloys contain small amounts of elements such as $\mathrm{Si}$ and $\mathrm{Mn}$. In this study, in order to observe the crystallization behavior of pure $\mathrm{Fe}, \mathrm{Cr}, \mathrm{C}$ ternary system,

\footnotetext{
*Corresponding author: 19042005@mmm.muroran-it.ac.jp
} 
samples were prepared using pure metals. In this study, after examining the internal structure using pure ternary samples, melting experiments with a CLSM Microscope were conducted to investigate the growth process of $\mathrm{M}_{7} \mathrm{C}_{3}$ carbide.

\section{Experimental Method}

\subsection{Experimental sample}

Materials used to make the $\mathrm{Fe}-\mathrm{C}-\mathrm{Cr}$ alloy were pure iron, pure chromium, and graphite plates, respectively. All materials have a purity of $99.9 \%$ or more. It is assumed that the composition of the sample to be prepared melts in the high temperature image furnace of the CLSM. From the liquid phase area projection of the $\mathrm{Fe}-\mathrm{C}-\mathrm{Cr}$ system and the $\mathrm{Fe}-\mathrm{Cr}$ system phase diagram (Baniff et al., 2001), the weight ratio is set to $\mathrm{Fe}: \mathrm{C}: \mathrm{Cr}=55: 5: 40$. This composition is in the hypereutectic composition range, and it is assumed that the sample is completely melted at $1600^{\circ} \mathrm{C}$. Arc furnace (Nisshin Giken: model NEV-AD03) was used for sample preparation. Since the arc furnace can be heated up to $3000^{\circ} \mathrm{C}$, it is suitable for melting materials with high melting points of $\mathrm{Cr}$ and $\mathrm{C}$. Furthermore, since the inside can be replaced with an inert gas, the samples do not react with air during melting.

\subsection{Measurement Principle of Confocal Laser Scanning Microscope}

Structures of samples passing the process of melting and solidification were observed Confocal Laser Scanning Microscope (Lasertech YONEKURA VL2000DX SVF17SP). Figure 1 shows schematic diagrams of the CLSM and infrared image furnace. The CLSM is capable of real-time observation of molten metal under high temperature by combination of a microscope using a violet laser light source and a high temperature image furnace. A wavelength of light source of the microscope used the violet region at a wavelength of $405 \mathrm{~nm}$. Therefore, compared with the Optical Microscope which irradiates light uniformly, reflected light with less scattered light is obtained. The light reflected from the surface of the sample follows the same path and is split by the beam splitter. Then it is collected by the light detector. A pin hole is placed in front of the

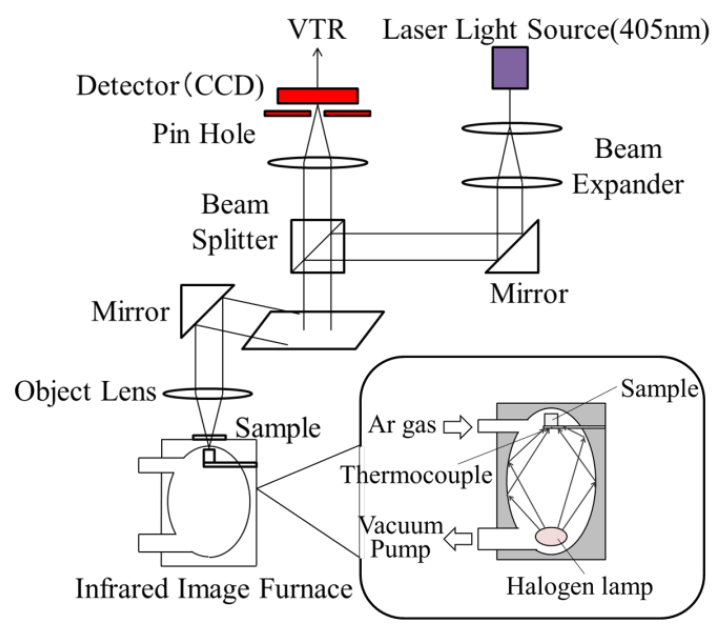

Figure 1. Overview of CLSM

light detector, which makes it possible to detect light only at a focused position. Therefore, observation can be performed without the influence of radiation (Shibata and Emi, 1997). The high-temperature image furnace has an elliptical inside and is coated with gold. Infrared light emitted from a halogen lamp installed at the bottom reflects inside the furnace and it is heated by collecting it on the installed sample. Since the inside is replaced with Ar gas, the molten metal does not react with air. A thermocouple is attached to the sample holder on which the sample is placed, so the furnace temperature can be measured in real time.

\subsection{Experimental procedure}

XRD (Rigaku Ultima IV) was used for the identification of the compound inside a sample. The XRD is an apparatus for performing an analysis by irradiating a crystalline substance with $\mathrm{X}$-rays and reading diffracted $\mathrm{X}$-rays. The phase state used $\mathrm{Cu}$ spheres at a speed of $2.0^{\circ} / \mathrm{min}$ in the range of $10^{\circ}$ to $100^{\circ}$. EPMA (JEOL JXA $8900 \mathrm{R}$ ) was used for elemental analysis and surface analysis of samples.

The experimental conditions using CLSM are shown in Table 1. The Fe-C-Cr alloy was heated to $1550^{\circ} \mathrm{C}$ in a high temperature imaging furnace and held for 5 minutes. The melted alloy was cooled at $60^{\circ} \mathrm{C} / \mathrm{min}$ or $30^{\circ} \mathrm{C} / \mathrm{min}$, and the solidification process was observed. When $\mathrm{M}_{7} \mathrm{C}_{3}$ carbides began to crystallize out, they were quenched at a cooling rate of $2600^{\circ} \mathrm{C} / \mathrm{min}$ to maintain the state of the structure. Optical Microscope (OM, OLYMPUS BX51) and Scanning Electron Microscope (SEM, JEOL JCM-5000) were used to observe the sample surface after conducting experiments by CLSM.

Table 1. Temperature condition by CLSM

\begin{tabular}{|c|c|c|c|c|}
\hline \multirow{2}{*}{$\begin{array}{l}\text { Sample } \\
\text { Temperature }\left({ }^{\circ} \mathrm{C}\right)\end{array}$} & \multicolumn{4}{|c|}{$\mathrm{Fe}-\mathrm{C}-\mathrm{Cr}$ alloy } \\
\hline & 1350 & 1550 & 1400 & 100 \\
\hline$\left({ }^{\circ} \mathrm{C} / \mathrm{min}\right)$ & 270 & 25 & $\begin{array}{l}-60 \\
-30\end{array}$ & -2600 \\
\hline Hold & 0 & 300 & 0 & 0 \\
\hline Frame count & 1 & 5 & 15 & 5 \\
\hline
\end{tabular}




\section{Results and Discussion}

\subsection{Microstructure of the prepared sample}

Figure 2 shows the internal structure of the $\mathrm{Fe}-\mathrm{C}-\mathrm{Cr}$
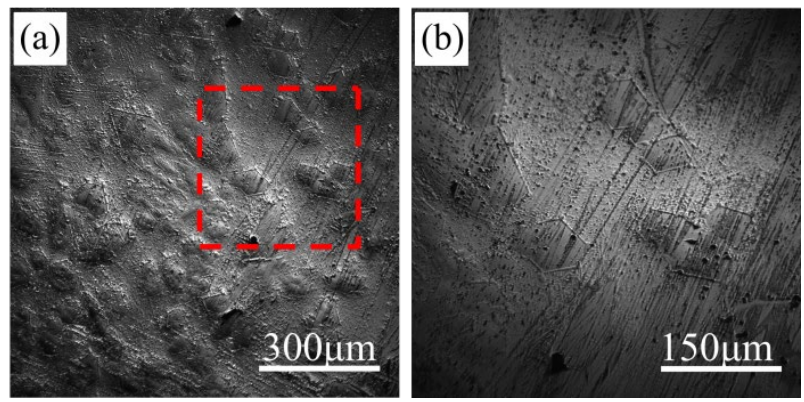

Figure 2. Structure observation by CLSM. (a) Structure of $\mathrm{Fe}-\mathrm{C}-\mathrm{Cr}$ alloy; and(b) Expansion picture of $\mathrm{Fe}-\mathrm{C}-\mathrm{Cr}$ alloy

alloy produced using an arc furnace. CLSM was used for observation. Figure 2(a) shows the internal structure of the $\mathrm{Fe}-\mathrm{C}-\mathrm{Cr}$ alloy. Hexagonal crystals are crystallized throughout the sample. From the crystal shape, it is thought that $\mathrm{M}_{7} \mathrm{C}_{3}$ carbide is crystallized. Figure 2(b) is an enlargement of the position shown by the square in Figure 2(a). The size of $\mathrm{M}_{7} \mathrm{C}_{3}$ carbide was about $50 \mu \mathrm{m}$.

\subsubsection{Analysis by $X R D$}

Figure 3 shows the results of $\mathrm{Fe}-\mathrm{Cr}-\mathrm{C}$ alloy by XRD. Figure 4 shows the peak tendency of $\mathrm{Cr}$ carbides $\mathrm{Cr}_{7} \mathrm{C}_{3}$ and $\mathrm{Cr}_{23} \mathrm{C}_{6}$ in the database inside the XRD. The highest peak appears in the vicinity of $45^{\circ}$ along the horizontal axis, and the peak is generally observed at similar positions. However, in Figure 3, a peak appears at $0^{\circ}$ to $20^{\circ}$. This seems to be the peak due to the sample fixing material fixed when analyzing the $\mathrm{Fe}-\mathrm{Cr}-\mathrm{C}$ alloy. Hence, $\mathrm{Cr}$ carbides $\mathrm{Cr}_{7} \mathrm{C}_{3}$ and $\mathrm{Cr}_{23} \mathrm{C}_{6}$ exist in the prepared $\mathrm{Fe}-\mathrm{Cr}-\mathrm{C}$ alloy, and they mix with $\mathrm{Fe}$ to form $\mathrm{M}_{7} \mathrm{C}_{3}$ and $\mathrm{M}_{23} \mathrm{C}_{6}$.

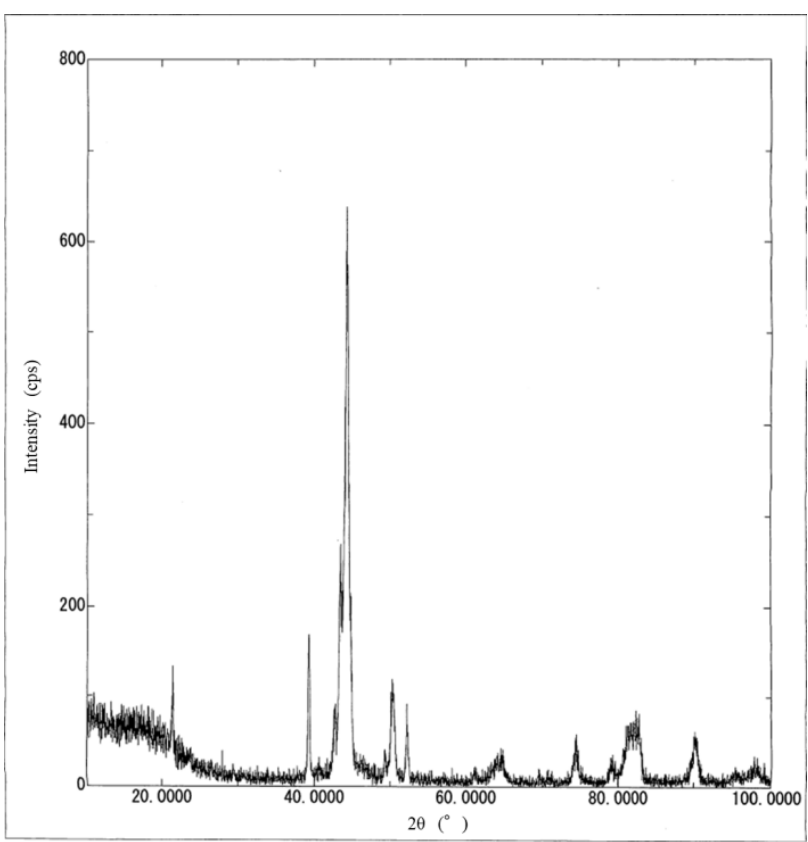

Figure 3. Analysis of Fe-C-Cr alloy by XRD

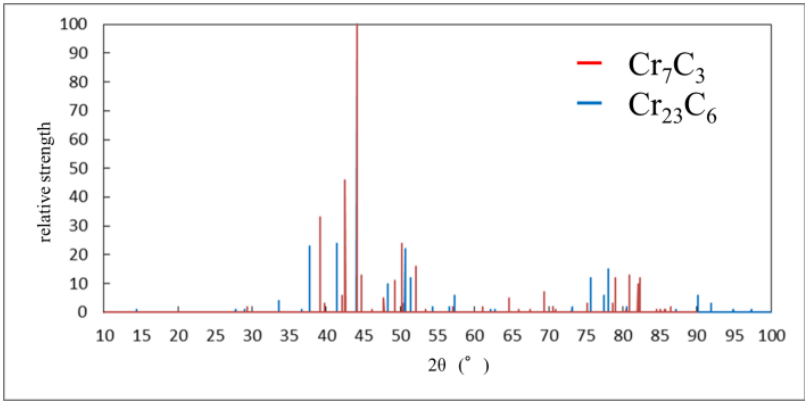

Figure 4. X-ray peak trend of $\mathrm{Cr}_{7} \mathrm{C}_{3}$ and $\mathrm{Cr}_{23} \mathrm{C}_{6}$

\subsubsection{Analysis by EPMA}

From qualitative analysis and quantitative analysis by EPMA, it was confirmed that only three types of $\mathrm{Fe}, \mathrm{C}$ and $\mathrm{Cr}$ were present in the internal structure of the $\mathrm{Fe}-\mathrm{C}-\mathrm{Cr}$ alloy and contained no impurities. Figure 5 shows the results of area analysis by EPMA using Fe-C-Cr alloy. $\mathrm{M}_{7} \mathrm{C}_{3}$ carbides are observed, and the cross section is hexagonal, with a hollow at the center. Figure 5(a)-(c) shows the color maps of $\mathrm{Fe}, \mathrm{C}$, and $\mathrm{Cr}$, respectively. Most of $\mathrm{M}_{7} \mathrm{C}_{3}$ carbides are occupied by $\mathrm{Cr}$, and most of matrix structure and around $\mathrm{M}_{7} \mathrm{C}_{3}$ carbides are Fe. C was included evenly. 


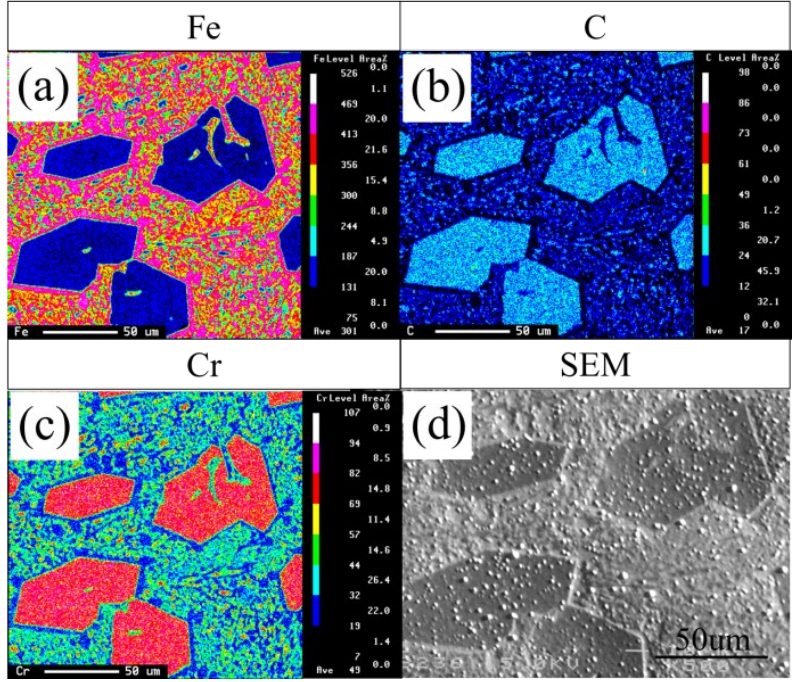

Figure 5. Area analysis of Fe-C-Cr alloy. (a) Color map of Fe, (b) Color map of C, (c) Color map of Cr, and (d) SEM image of $\mathrm{Fe}-\mathrm{C}-\mathrm{Cr}$ alloy

\subsection{Solidification process observation of $\mathrm{Fe}-\mathrm{Cr}-\mathrm{C}$ alloy}

\subsubsection{Solidification process with a cooling rate of $60^{\circ} \mathrm{C} / \mathrm{min}$}

Figure 6 shows the solidification process at the cooling rate of $60^{\circ} \mathrm{C} / \mathrm{min}$. In Figure $6(\mathrm{a})$, the corner portion of the $\mathrm{M}_{7} \mathrm{C}_{3}$ carbide is crystallized. As cooling is continued as shown in Figure 6(b)-(c), $\mathrm{M}_{7} \mathrm{C}_{3}$ carbides form a hexagon so as to connect the corners. However, not all $\mathrm{M}_{7} \mathrm{C}_{3}$ carbides form a perfect hexagon. In Figure 6(d), a gap is present between the $\mathrm{M}_{7} \mathrm{C}_{3}$ carbides at the positions shown by squares at $1466.5^{\circ} \mathrm{C}$. This is considered to be the same phenomenon as the previous work by Liu et al. (2016). It was found by observation that while $\mathrm{M}_{7} \mathrm{C}_{3}$ carbides form hexagons, the corners are immediately connected, but it takes time to fill the gaps existing between the carbides. The size of the $\mathrm{M}_{7} \mathrm{C}_{3}$ carbides was about $50 \mu \mathrm{m}$, similar to those seen in Figure 2 and Figure 5. Figure 7 shows the solidification process in another observation plane. Rectangular crystals are stretched. This crystal is considered to be $\mathrm{M}_{7} \mathrm{C}_{3}$ carbide because it is the same as the temperature zone where $\mathrm{M}_{7} \mathrm{C}_{3}$ carbide crystallizes. Since $\mathrm{M}_{7} \mathrm{C}_{3}$ carbides preferentially grow along the c-axis, they become hexagonal columnar crystals. Therefore, this elongated shape is considered to be due to growth along the preferred orientation. From these results, the growth process of $\mathrm{M}_{7} \mathrm{C}_{3}$ carbide is predicted as shown in Figure 8. First, corner portions of $\mathrm{M}_{7} \mathrm{C}_{3}$ carbides grow in the preferential growth direction (Figure 6(a)), and hexagons are formed so as to connect the subsequent corners. $\mathrm{M}_{7} \mathrm{C}_{3}$ carbides have a preferred growth orientation in the c-axis, so they become elongated and become hexagonal columnar crystals.
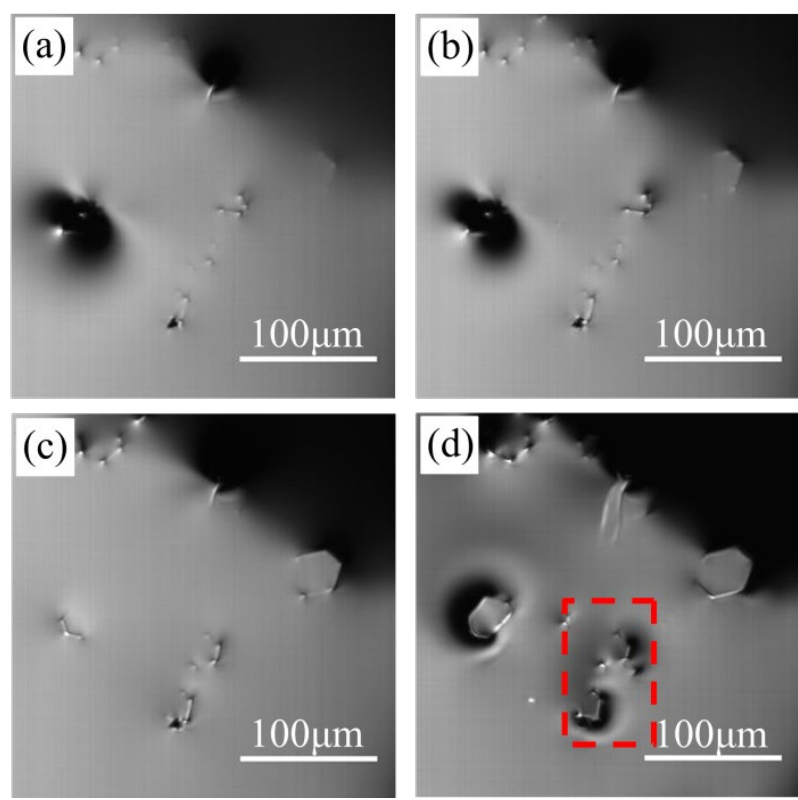

Figure 6. Solidification image of $\mathrm{M}_{7} \mathrm{C}_{3}$ at cooling rate $60^{\circ} \mathrm{C} / \mathrm{min}$. (a) $1489.6^{\circ} \mathrm{C}$, (b) $1488.0^{\circ} \mathrm{C}$, (c) $1473.8^{\circ} \mathrm{C}$, and (d) $1466.5^{\circ} \mathrm{C}$
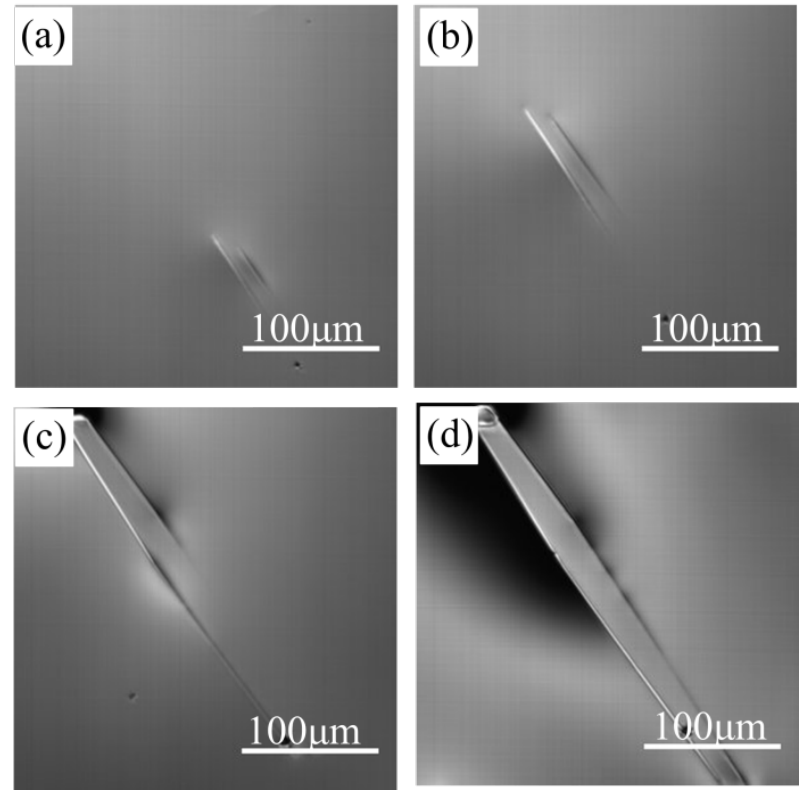

Figure 7. Solidification image of $\mathrm{M}_{7} \mathrm{C}_{3}$ for cooling rate $60^{\circ} \mathrm{C} / \mathrm{min}$. (a) $1494.8^{\circ} \mathrm{C}$, (b) $1493.4^{\circ} \mathrm{C}$, (c) $1482.2^{\circ} \mathrm{C}$, and (d) $1466.1^{\circ} \mathrm{C}$ 


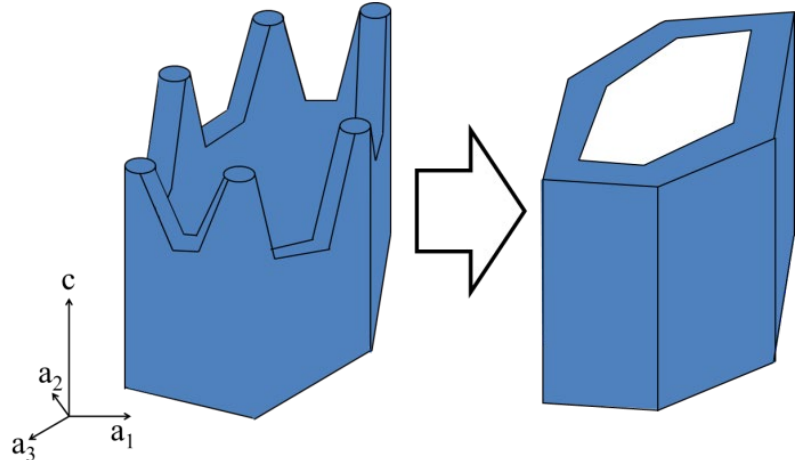

Figure 8. Schematic diagrams of the $\mathrm{M}_{7} \mathrm{C}_{3}$ carbides growth process for cooling rate $60^{\circ} \mathrm{C} / \mathrm{min}$

\subsubsection{Solidification process with a cooling rate of $30^{\circ} \mathrm{C} / \mathrm{min}$}

Figure 9 shows the solidification process at a cooling rate of $30^{\circ} \mathrm{C} / \mathrm{min} . \mathrm{M}_{7} \mathrm{C}_{3}$ carbide crystallizes out as $\mathrm{M}_{7} \mathrm{C}_{3}$ is surrounded from the outside in Figure 9(a). Since this is a behavior not seen in the solidification process at a cooling rate of $60^{\circ} \mathrm{C} / \mathrm{min}$, it is considered that there is another crystallization behavior in the solidification process at a cooling rate of $30^{\circ} \mathrm{C} / \mathrm{min}$. When the cooling is continued as shown in Figure 9(b)-(d), it appears to form a hexagon, but as in Figure 6(d), a gap is present without forming a complete hexagon. The size of $\mathrm{M}_{7} \mathrm{C}_{3}$ carbide was about $50 \mu \mathrm{m}$. Now, Figure 10 shows the solidification process in another observation plane. The arrows indicate the direction in which the crystals were crystallized. From the place where it crystallized out in Figure 10(a), it can be seen that the crystals are growing in a hexagonal shape gradually. Therefore, it is considered that crystallization as in the growth model of Figure 8 is not performed. Thus, it is considered that

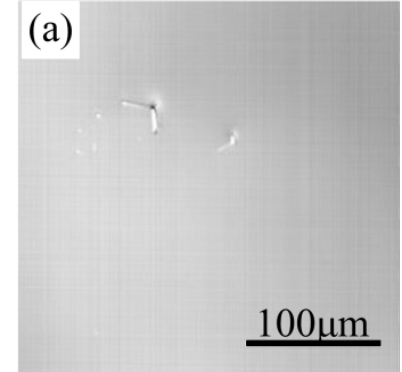

(c)

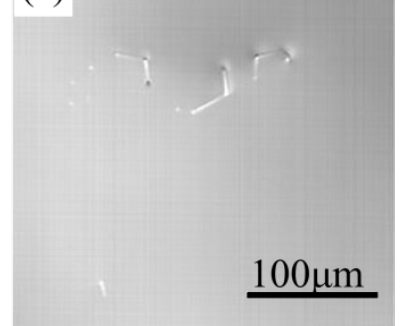

Figure 9. Solidification image of $\mathrm{M}_{7} \mathrm{C}_{3}$ at cooling rate $30^{\circ} \mathrm{C} / \mathrm{min}$. (a) $1494.8^{\circ} \mathrm{C}$, (b) $1493.4^{\circ} \mathrm{C}$, (c) $1482.2^{\circ} \mathrm{C}$, and (d) $1466.1^{\circ} \mathrm{C}$

there is another pattern in the crystallization behavior of the $\mathrm{M}_{7} \mathrm{C}_{3}$ carbide. An expected growth process of another pattern of $\mathrm{M}_{7} \mathrm{C}_{3}$ carbide is shown in Figure $11 . \mathrm{M}_{7} \mathrm{C}_{3}$ carbides grow diagonally to the observation plane. First, only a few areas can be observed, and most tissues are hidden in the fluid (Figure10(a)). After that, the tissue in the liquid starts to grow, and eventually gets a hexagonal shape.
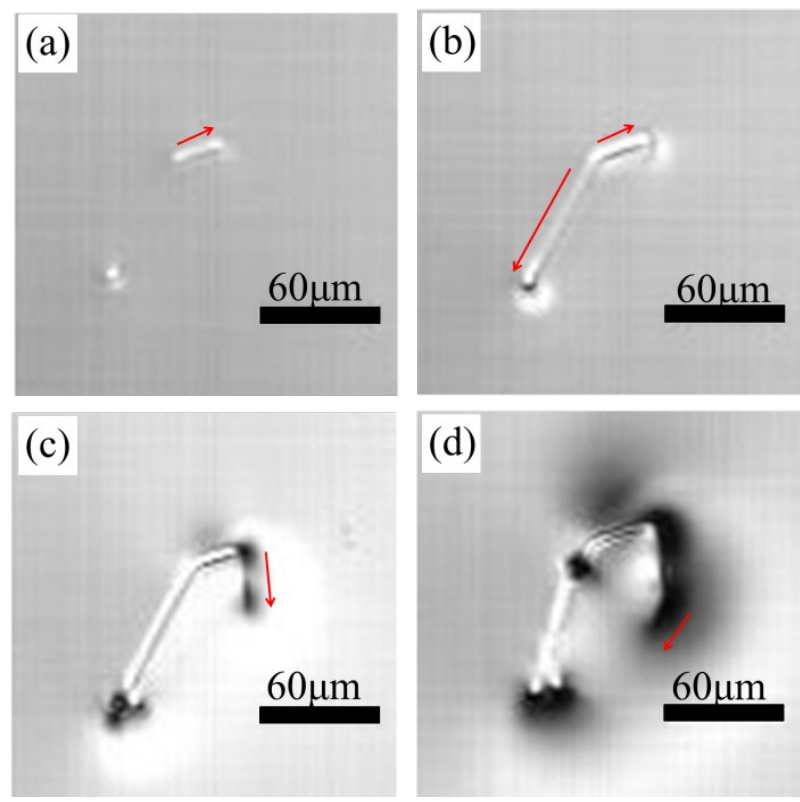

Figure 10. Solidification image of $\mathrm{M}_{7} \mathrm{C}_{3}$ at cooling rate $30^{\circ} \mathrm{C} / \mathrm{min}$. (a) $1509.9^{\circ} \mathrm{C}$, (b) $1503.6^{\circ} \mathrm{C}$, (c) $1498.9^{\circ} \mathrm{C}$, and (d) $1485.9^{\circ} \mathrm{C}$
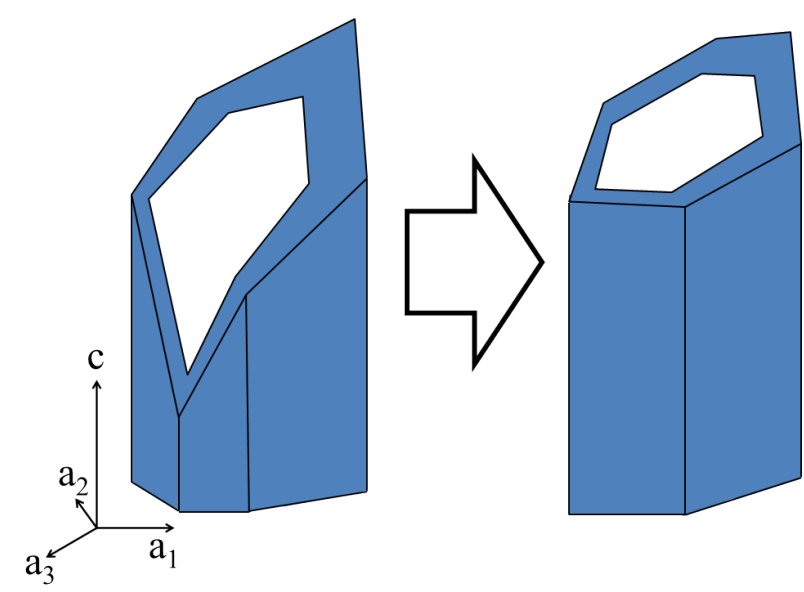

Figure 11. Schematic diagrams of the $\mathrm{M}_{7} \mathrm{C}_{3}$ carbides growth process for cooling rate $30^{\circ} \mathrm{C} / \mathrm{min}$

\subsection{Structure observation after melting}

Figure 12 shows how the sample surface after the melting experiment was observed using $\mathrm{OM}$. The $\mathrm{M}_{7} \mathrm{C}_{3}$ carbide was found to have more crystallization in the transverse direction than the crystallization in the longitudinal direction. Figure 13 shows how the sample surface after the experiment is observed by SEM. As 
shown in Figure 13(a), it can be seen that the entire sample is covered with $\mathrm{M}_{7} \mathrm{C}_{3}$ carbide in the lateral direction. The $\mathrm{M}_{7} \mathrm{C}_{3}$ carbide from the longitudinal direction is seen at the position enclosed by the square. The $\mathrm{M}_{7} \mathrm{C}_{3}$ carbides shown in Figure 13(b) appears to have a difference in height between the inside and the outside of the carbides. From the change of the height and the result of the melting experiment, it is thought that the formation of $\mathrm{M}_{7} \mathrm{C}_{3}$ carbide is formed preferentially in the outside and the formation of the inside is delayed.

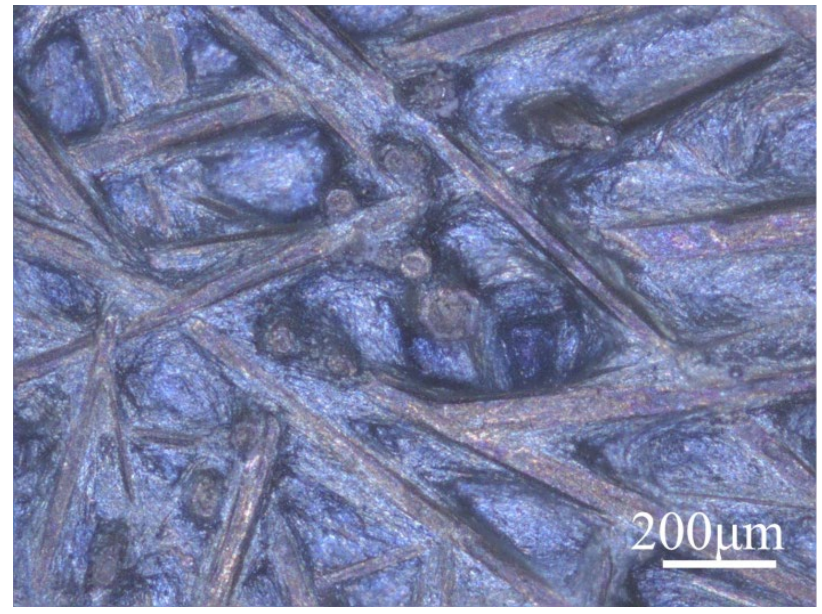

Figure 12. OM image of Fe-C-Cr alloy
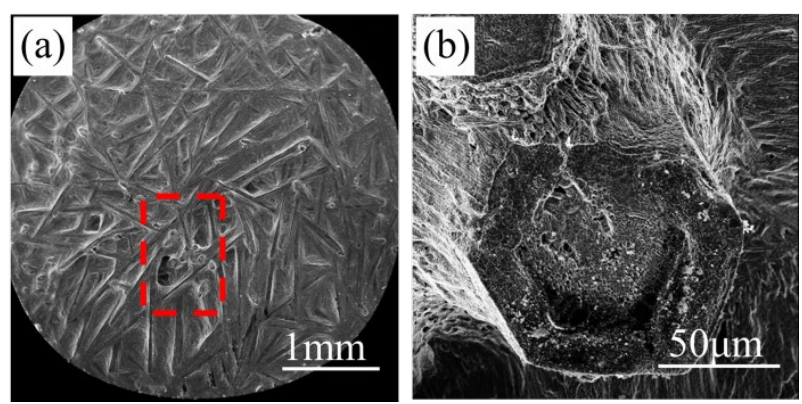

Figure 13. SEM image of Fe-C-Cr alloy (a) Sample Overall picture, and (b) Unevenness of $\mathrm{M}_{7} \mathrm{C}_{3}$

\section{Conclusions}

- As Fe-C-Cr alloy observed by the CLSM, the crystallization of $\mathrm{M}_{7} \mathrm{C}_{3}$ carbide was confirmed during the solidification process.

- Corners of the Hexagonal structure grew in the preferred orientation direction of $\mathrm{M}_{7} \mathrm{C}_{3}$ carbide at $60^{\circ} \mathrm{C} / \mathrm{min}$. After that, the $\mathrm{M}_{7} \mathrm{C}_{3}$ carbide formed to connect between the corners.

- At a cooling rate of $30^{\circ} \mathrm{C} / \mathrm{min}, \mathrm{M}_{7} \mathrm{C}_{3}$ carbides grew in oblique direction to the observation area. At the beginning, the structures were hidden in the fluid. But the structures started to grow, the shape of the hexagon became eventually.

- Since hexagonal structure arose a difference in height between the outside and the inside observed by $\mathrm{OM}$ and SEM. $\mathrm{M}_{7} \mathrm{C}_{3}$ carbides grew from the outside in the solidification process.

\section{Reference}

Baniff, O. A., K. Enami, S. Nagasaki, and A. Nshiwaki; Iron-Alloy Phase Diagrams-from 2-Element System-7 2-Element System, pp. 20-23, and pp. 212-217, Agune Technology Center, Tokyo, Japan (2001)

Liu, S., Y. Zhou, X. Xing, J. Wang, X. Ren, and Q. Yang; "Growth Characteristics of Primary $\mathrm{M}_{7} \mathrm{C}_{3}$ Carbide in Hypereutectic Fe-Cr-C Alloy," Scientific Reports, 6,1-8 (2016)

Sato, T., T. Nishizawa, and J. Ishihara; "A Study on Hardness of Carbides in Iron and Steel," J. JPN. INST. MET., 7, 404-405 (1958)

Shibata, H. and T. Emi; "Confocal Scanning Laser Microscope Technique to "In-Situ" Observe Phase Transformations and Behaviors of Nonmetallic Inclvsions and Precipitates in Metals at Elevated Temperatures," Materia Japan, 36, 809-813 (1997)

Tang, X. H., R. Chung, C. J. Pang, D. Y. Li, B. Hinckley, and K. Dolman; "Microstructure of High (45 wt.\%) Chromium Cast Irons and Their Resistances to Wear and Corrosion," Wear, 271, 1426-1431 (2011)

Tong, C. P., T. Suzuki, and T. Umeda; "The Influence of Chemical Composition on Eutectic Solidification and Structures of High Chromium Cast Iron," Casting, 62, 130-137 (1990a)

Tong, C. P., T. Suzuki, and T. Umeda; "High Chromium Cast Iron Rolls for Steel Rolling Mills," Casting, 62, 925-926 (1990b) 